\title{
Solid Waste Management in the Town of Maradi in Niger Republic
}

\author{
Hassidou Saidou*, Soulé Aminou \\ Faculty of Sciences and Technology, University of Maradi, Maradi, Republic of Niger \\ Email: *saidouhassidou@gmail.com, saidouhassidou@yahoo.fr
}

Received 22 February 2015; published 17 April 2015; published 20 April 2015

Copyright (C) 2015 by authors and Scientific Research Publishing Inc.

This work is licensed under the Creative Commons Attribution International License (CC BY). http://creativecommons.org/licenses/by/4.0/

c) (i) Open Access

\begin{abstract}
As in many towns of African countries, the waste management, in particularly solid constitutes a major problem for the municipal authorities of Maradi. The aim of this study is to make a diagnosis of the present system of waste management in the town of Maradi. To achieve this goal, interviews with municipal authorities, cleaning up and health technicians have been made, as well as investigations among households. According to the health technicians of the town, the causes due to the problem of waste management in Maradi town are: collecting capatown insufficient, lack of effective sensitization of people, undeveloped and uncontrolled rubbish dumps, lack of gutter and its maintenance, and insufficient and unqualified human resources. As to the authorities, they denounce always the attitude and the behavior of citizens on the waste issue. The waste evacuation is done by municipal collecting or by depositing in wild rubbish dump. Some people eliminate their waste by burning or duping in the streets or in their houses. According to our investigations, $52 \%$ of population evacuates their waste daily. The satisfaction rate of municipal collecting is for $32 \%$. The analysis showed that the present system of waste management in Maradi town was failing. As to solutions, we proposed to equip the technical offices with appropriated material and financial means, reinforce the involved actor's capacities and make in application the operatives regulations for the waste management.
\end{abstract}

\section{Keywords}

Solid Waste Management, Maradi, Niger Republic

\section{Introduction}

Waste management has an international history, social and cultural representations. Indeed, between 1770 and 1860, the value of excreta, particularly urban excreta, thanks to its agricultural and industrial importance in-

${ }^{*}$ Corresponding author. 
creased. Next the birth of waste in the form of abandoned junk and materials from 1870 to 1960 will be presented. Since 1960s and 1970s, the environmental crisis has translated into a waste crisis for which only imperfect solutions have been found [1].

Waste generation is closely linked to population, urbanization and affluence [2]. It is generated universally and is a direct consequence of all human activities [3]. Waste generation varies as a function of affluence, however, regional and country variations can be significant, as generation rates within the same town. Waste generation in sub-Saharan Africa is approximately 62 million tons per year. The annual waste generation in East Asia and Pacific Region is approximately 270 million tons per year. This quantity is mainly influenced by waste generation in China, which makes up 70\% of the regional total. In Eastern and Central Asia, the waste generated per year is at least 93 million tones. The total amount of waste generated by Latin America and Caribbean is 160 million tons per year [3]. High-income countries produce the most waste per capita, while low-income countries produce the least solid waste per capita [3]. Australia generated approximately 32.4 million tons of solid waste in 2002-2003. Of this amount, approximately 27 percent was municipal waste, 29 percent was from the commercial and industrial sector, and 42 percent was from the construction and demolition sector. Overall, approximately 1.6 tons of waste was for every Australian in 2002-2003 [2]. The total daily waste generation was 25 tons in Bhaktapur (Nepal) in 2008. The average per capita household waste generation rate was $0.30 \mathrm{~kg}$ per day. The composition of household waste at source was: 75 percent organic or biodegradable waste, 2.25 percent paper, 3 percent textiles, 3.4 percent plastic, 0.3 percent metal, 1.05 percent glass, 11.0 percent construction debris and 4.0 percent other materials [4]. Some $80 \%$ of municipal waste in Berlin is domestic waste, and the remaining 20\% is trade or industrial waste [5]. A quantity of 90 million tons of waste was generated in Sweden in 2002. Resource extraction, mainly mining, generated 54 million tons of waste. Manufacturing industry produced 19 million tons [6]. In Nigeria, the average waste generation rate was known to be $0.49 \mathrm{~kg}$ in 1991 [7].

Waste generation rates could vary depending on the season, month and day of the week [8]. However, the Japan International Cooperation agency did not find conventional season-specific impacts on household waste generation in KMC. Instead, they found $223 \mathrm{~g} / \mathrm{capita} / \mathrm{day}$ with $248 \mathrm{~g} /$ liter of bulk density among 40 households examined in April 2004 (dry season) and 248 g/capita/day with a bulk density of 174 g/L for 400 households studied in September 2004 (wet season). It varies also considerably according to diets (e.g. changes from fresh vegetable to packaged aids goods) and even the day of the week. An average of around $0.5 \mathrm{~kg} / \mathrm{capita} / \mathrm{day}$ is common in low-income cities. Waste densities also vary considerably. Densities for low-income cities are usually around $200-400 \mathrm{~kg} / \mathrm{m}^{3}$ [9].

Human waste management is one of the most important public health programs. It is considered by world health organization as one of the basic steps to be taken to safeguard our environment [10]. Therefore, activities should be prioritized according to present and future health hazards of different waste types and sources. Activities are likely to focus on clearing of existing scattered waste and managing waste from households and markets [9]. Thus, after generation, waste should be collected. Waste from homes is generally collected by local authorities through regular waste collection, or by special collections for recycling. Within hot climates such as that of African and Caribbean the waste should be collected at least twice a week to control fly breeding, and the harbouring of other pests in the community. After collection, waste should be transported, by selecting vehicles, to final disposal. Therefore, accessible areas and distance between collection and disposal points should be considered [9]. As a medium-term solution, larger-scale landfill pits can be constructed as disposal. However, without leachate (liquid runoff) treatment these are not suitable for long-term use. They should be situated at least $1 \mathrm{~km}$ downwind settlements, at a location selected in consultation with the population. They should also be situated at downhill of water sources and at least $50 \mathrm{~m}$ from surface water sources [9].

In most developed and developing countries with increasing population, prosperity and urbanization, it remains a major challenge for municipalities to collect, recycle, treat and dispose of increasing quantities of solid waste and wastewater. A cornerstone of sustainable development is the establishing of affordable, effective and truly sustainable waste management practices in developing countries. It must be further emphasized that multiple public health, safety and environmental co-benefits accrue from effective waste practices which concurrently reduce GHG emissions and improve the quality of life, promote public health, prevent water and soil contamination, conserve natural resources and provide renewable energy benefits [11]. To achieve this goal, several efforts must be consented: human resources in quantity and quality, and equipment maintenance. Indeed, according to WHO/UNEP approximately 2.5 workers are required for 1000 municipality members [12]. Protec- 
tive clothing and equipment need to be considered (e.g. gloves, boots, and visibility jackets) [9]. Waste can be often corrosive, so it is important to paint all metal waste management equipment and to wash it frequently. Such activity can significantly increase the life of equipment [9].

Several works are focused on waste management in African countries [13]-[16]. This study aimed to investigate how solid waste is managed in the town of Maradi, economic capital of Niger Republic, a West African country.

\section{Material and Methods}

\subsection{Presentation of the Town of Maradi}

Our study took place in the town of Maradi. It is situated in south-central of Niger Republic in the department of Madarounfa between parallels $13^{\circ}$ and $15^{\circ} 26^{\prime}$ north latitude and meridians $6^{\circ} 16^{\prime}$ and $8^{\circ} 36^{\prime}$ east longitude. It is located at about $650 \mathrm{~km}$ east of the capital Niamey on National Highway No. 1 and about $45 \mathrm{~km}$ from the Federal Republic of Nigeria [17].

Moreover, the town of Maradi is bounded on the north by the urban municipality of Tibiri, to the west by the rural municipalities of Sarkin Yamma, and Safo and, to the east by the rural municipality of Djiratawa. Created by the law 2002-014 of June 2002, the town of Maradi is divided into three districts, each of which is administered by a town councilor [18]. The population of the town of Maradi is estimated in 2010 at 200,015 inhabitants [19].

\subsection{Administrative Division of the Town}

The town of Maradi has 17 districts unevenly distributed in three municipalities (PDC 2010):

Municipality I (6 districts): Bouzou dan zambadi, aladey Soura, Soura bildi, Mazadou jika, Nouveau Carré and Zaria 1.

Municipality II (4 districts): Zaria 2, Sabon Gari, Bagalam and Makoyo.

Municipality III (7 districts): Ali dan sofo, Bourja, Maradaoua, Dan Goulbi, Assaou, Limantchi and Yandaka (Figure 1).

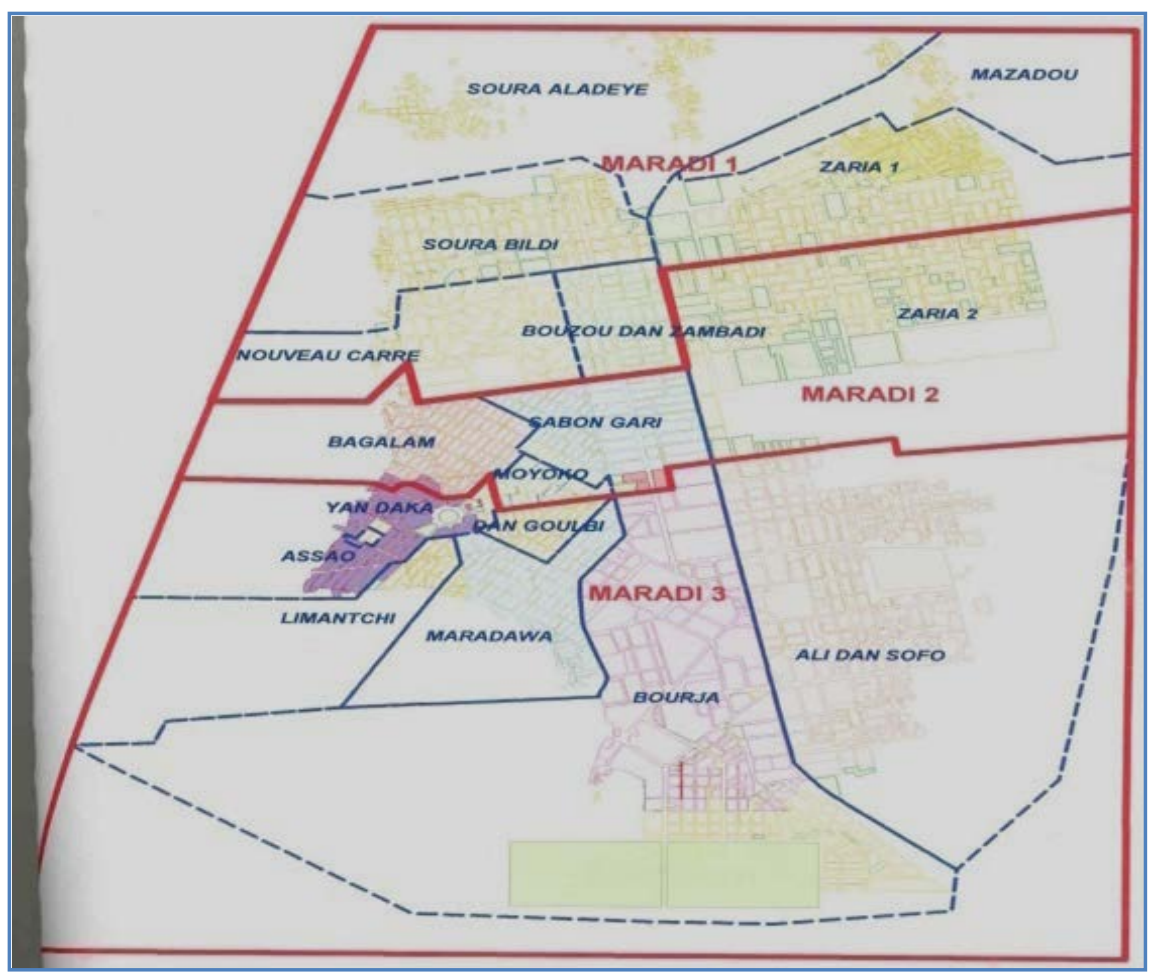

Figure 1. Map of Maradi town. 


\subsection{Human Environment}

\subsubsection{Population}

According to demographic projections from the National Institute of Statistics (INS) in 2009, the population of Maradi town is estimated to be 193,785 , with a density of 114.5 inhabitants $/ \mathrm{km}^{2}$ and an annual growth rate of $3.6 \%$, however with significant disparities between municipalities. Indeed, the population is concentrated in the old group of older neighborhoods (Maradaoua, Limantchi, Yandaka, Bagalam Dan Goulbi and Mokoyo).

In general, in the Maradi town, the average size is 7 people per household with a total fertility rate of 7.5.

\subsubsection{Socioeconomics Activities}

As everywhere in Niger Maradi's economy is based largely on the primary sector, mainly agriculture and livestock which occupy more than $90 \%$ of industry assets. However, one feature of the Maradi town activity is business which covers about $79.5 \%$ of working individuals in the population. In women, the trade represents $92.1 \%$ of their modern activities. However, there is a dynamic activities such as crafts and rural exodus (men) that contribute significantly to the economy of the populations in the areas of tanning, despite the informality and lack of organization of these sectors [20].

\subsection{Methodological Approach}

To carry out this work, the methodology is based on three main pillars:

The document and literature search;

The interviews in key policy makers, technical experts and waste management in Maradi;

The household surveys.

In the end, all obtained data is processed, analyzed and presented in tables.

Equipment used: survey records, maintenance records, internet, camera, computer... etc.

\subsubsection{Literature Search}

It is to consult the literature on solid waste management of the Technical Head office of the three municipalities and the Central municipality, the general direction of the Environment, Non Government Organizations (NGO), some memories of the University of Maradi and Niamey and some background research on the internet.

\subsubsection{Interviews with Actors}

We have had discussions with the municipal authorities responsible for the management of waste, responsible for management of the environment involved in waste management. We also talked with the leaders of structures pre-collection and waste collection.

\subsubsection{Household Surveys}

These surveys were conducted in 340 households equally distributed in all 17 districts of the town, 20 households per district. These surveys enabled us to understand the behavior, practices and attitudes of populations in terms of waste management in the town of Maradi.

\subsubsection{Field Visits}

These visits allowed us to have a clear idea of the ground realities. We have, in this framework, through the streets of the town of Maradi, considered the status of garbage cans, intermediate dumps authorized and unauthorized (uncontrolled dumps).

\section{Results}

\subsection{Diagnosis of Current Waste Management in the Town of Maradi}

\section{Strengths and Weaknesses of the Current System}

1) Strengths

In the town of Maradi, diagnosis highlighted the following strengths:

Despite their limited resources and their expertise, both technical and organizational, associative and munici- 
pality dynamics that exist in Maradi are already proving particularly volunteers, courageous and imaginative to initiate activities in the improvement of the living quarters.

The private sector showed great motivation to invest in the proposed local urban services to the population, despite the administrative and financial difficulties of all kinds.

2) Weaknesses

The diagnosis also revealed significant weaknesses whose weight will slow the proper functioning of the current system.

First, the extreme confusion among public institutions, both central and municipal governments that will help:

a) fragmented efforts in a context of weak capacity,

b) reluctance external cooperation partners to finance the sector of the urban environment despite the scale of the needs,

c) weak legislation and regulation in waste management.

Worse, the both central and municipal political will to clean up the practices of the administration, is not up to the adverse consequences of these practices in respect of the urban environment and living conditions urban populations.

The general lack of control over financial transparency and post-evaluation of the actions undertaken, both in public institutions and in municipality based organizations and private companies, is not conducive to improving practices.

Finally, if civil society is beginning to organize itself, through its individual and municipality initiatives, it is particularly little support from the government, both in terms of moral, technical and financial perspective.

Central authorities as much as municipal of Maradi town often complain about the behavior of people in the town, which is particularly detrimental to the safety of neighborhoods in particular and that of the town in general. For this we note that:

- The level of health awareness of the population remains very low: they make little connection between their bad sanitation practices (in the broad sense that is to say, about the wastewater, stormwater and garbage) and the frequency of the most common diseases.

- More importantly, among those who are aware of the practices are not much better. Is the resignation to fate or disillusionment with the ineffectiveness of individual efforts at the lack of collective effort?

- Indeed, public confidence in the use of government has largely blunted, and a significant proportion is now believed that the associations and the private sector have an important role to play.

- The level of information on regulations is practically inexistent.

- But still, we find that people now recognize their responsibility in waste management and in finding solutions to the problems that exist there. They are ready to do something, and sometimes do already, as in the case of their rain protection (case of Zaria1, Mazadou and Soura Aladey). In these areas some householders paying the drivers of dump trucks to bring the waste collected for rambler ravines next to their concessions. Their problem is that they are on their own, without technical or financial assistance from the government.

- Surveys have shown that, especially, on the one hand people are largely willing to contribute financially to improving their environment when reliable services and benefits offered to them (this is already the case with the pre-collection garbage), and secondly, they have quite specific ideas about the desire for improvement if they could be listening and let them be involved in the elaboration of solutions.

\subsection{Result of Interviews with Municipal Authorities of the Town of Maradi}

The issue of waste management in Maradi has become worrisome to all relevant levels. To find a solution, it is necessary to identify the major causes that led to this situation. According to the hygiene and sanitation engineers of the town, causes related to this situation are: insufficient collection capacity (lack of resources), lack of effective awareness, badly managed and uncontrolled landfills and insufficient human resources abilities.

\subsubsection{Insufficient Collection Capacity}

In the different municipalities of the town, a system of waste collection by trucks has been set up, but this collection is often hampered by lack of sufficient financial resources which is manifested through lack of fuel, lack of vehicle maintenance and prolonged equipment failures. Indeed, the municipality provides a shoestring budget for this sector and collectors fail to remove all solid waste from the town. 


\subsubsection{Lack of Effective Awareness of Population}

The success or failure of any waste management strategy depends, first of all, on the participation of the population. Awareness also helps accustom the population to a certain behavior as to the dates and places of waste disposal. Regarding the introduction of the curbside, municipalities should make awareness. However, regardless of the collection system introduced, training and awareness must take place, areas and neighborhoods should have the services responsible for this mission.

\subsubsection{Uncontrolled and Badly Managed Landfills}

Landfills are not well equipped to effectively receive all categories of waste. The trucks will dump waste in an uncontrolled manner; there is waste that is deposited on the access road. Irregular landfills along the access road pose a risk of cork, permanent disability for truck traffic. Exploiting these landfills, as currently practiced, with an irregular discharge, deserves to be controlled. These discharges are regularly searched by the poor to find items that can be still usable for men and animals, which is a major health risk for the population of the town. This is the case of the uncontrolled discharge, "kadro", located next to the market and landfill located on the road of Dan Issa at the entrance to the town of Maradi (southern).

1) Uncontrolled dumps

Wild dumps are; mostly, located along highway frequented by pedestrians and cyclists, near homes and are even larger than the population density is high, and the evacuation is random. The risk of contamination is very important, especially for children playing often in piles of garbage. In addition to disease, the accumulation of these wastes can cause unhealthy in children, many accidents: burns, wounds with glass or metal, toxic ingestions, falls, and risk of tetanus.

\subsubsection{Inadequate Human Resources Capacities}

Units that work to hygiene and sanitation services in the departments responsible for the management of the environment, whether at the regional office or town hall are not equipped enough to address the issue of waste management.

\subsection{Current Status of Waste Management System in Maradi Town}

\subsubsection{Pre-Collection}

Pre-collection is the door to door collection of waste; it is often initiated in the sub-region by private operators [21]. It provides support to households who are thus relieved of transporting their waste, from their concession for containers or garbage dumps. It also provides support to communities if it respects and ensures the proper management of waste collected: their evacuation to a container or an official dump, or possibly to a landfill. Finally, it generates a lot of local jobs and stimulates private enterprise. In Maradi, initiatives and experiences of pre-collection at the household level are multiple but are mostly ineffective. Many private operators, associations and NGOs have set up, but in a very disparate and without prior consultation. For these emerging organizations, the garbage is sometimes integrated with other activities in various fields such as education, the fight against poverty and unemployment; this is the case of the association, Garkuwa (Ali Dan Sofo district) in Municipality III, which is a Youth Association for the Fight against Poverty (AJLCP).

According to the officers of hygiene and sanitation services in different municipalities, we can raise the activity of the NGO RAIL, French Cooperation, the European Union, the AJLCP, the women's group, the radioclub, etc. These NGOs also play a role in educating households. The municipalities coordinate all activities of the structures.

Pre-collection structures work with a secretary and an accountant. The field agents are compounds of the garbage collection team and collectors. Collectors are responsible for collecting royalties' activities. Officers' cleanliness handles for the disposal of household garbage they empty into the carts. These agents are sometimes two per cart (usually a family man and his son or two brothers). The controller oversees the smooth running of field activities. Field officers pre-collection encounter several difficulties. These include the presence of other illegal providers, weak support of the people in the system of waste management for development of uncontrolled dumps and injuries due to some threat objects.

The pre-collection chain is not at all organized. Indeed, the structures act freely after authorization to practice officially issued by the authorities, but also sometimes informally. 
These private initiatives should be encouraged by municipalities who seek public support in waste management. This translates into financial support or material rewards and collaboration with technical services.

1) Example of pre-collection structure management (case of Municipality I)

The structure of pre-collection consists of carters that collect waste from households to containers. In the municipality I, three quarters receive currently this structure: Soura Bildi, Nouveau Carré and Bouzou Dan Zambadi. There are a total of 9 carters (donkey carts) and 6 women which are responsible for collecting royalties' activities (1000 FCFA per household). The work is done according a daily schedule and carters are distributed in team in the various streets of the three neighborhoods. Each team operates in a very definite street and has a number of materials such as peeled, rakes, etc.

As agents of cleanliness (AC) note that it is a group often very exposed to very high risk of disease through the activity they lead. Facility managers, aware of this fact, put sometimes available to their AC: boots, gans, and mufflers. The controllers have the responsibility to ensure the port of this equipment by each AC.

An example of monthly financial statement was given in Table 1:

Monthly wage of workers

- 1 carter: 30,000 FCFA/month

- 1 money collector: 20,000 FCFA/month

- 1 guardian: 20,000 FCFA/month

\subsubsection{Collection}

The collection consists of the collection of waste temporarily stored in different points of the town by municipal sanitation officers. The collection efficiency depends on the state of the collection points, the control of the sources and volumes of waste generated, the logistics implemented and the organization pickups (routes and schedules) and especially the destination of the waste collected.

In the town of Maradi, there are two official points of collection, the container and the official dump created in consultation with the heads of districts in order to compensate the lack of containers. These two collection points are recorded by local authorities and are subject to removal. It exists in the town another kind of collection point said wild dumps spontaneously created by people, and as we have seen merely multiply every day.

If the number of containers and official dumps are well known in municipalities (Table 2), it is not the same for wild dumps that are not listed and are not the subject of collection unless the volume is very important ( 1 time per three months in the Municipality III). Their proliferation has a real threat for local residents and the environment.

Most of the waste, ( $80 \%$ or $90 \%$ according to the Central municipality) are sold along the way, especially

Table 1. Financial results of the pre-collection in the month of September 2012.

\begin{tabular}{cc}
\hline Staff and Equipment & Salary and monthly expenses (in FCFA) \\
\hline 9 carters & 270,000 \\
6 money collectors & 120,000 \\
2 guards & 40,000 \\
Maintenance & 20,000 \\
Total expenditure & 450,000 \\
Total fee collected & 393,450 \\
\hline
\end{tabular}

Table 2. Number of containers per municipality.

\begin{tabular}{ccc}
\hline Municipality & Number of containers \\
\hline I & 15 \\
II & 20 \\
III & 53 \\
Total & 88 \\
\hline
\end{tabular}


along the main roads by drivers of municipality trucks to farmers as "amendment". A portion is also sold as "fill" in the gully by runoff from rainfall (case of Mazadou Jika and Soura Alladey) especially near the Maradi lake (Goulbi) for surrounding areas as Soura Bildi, Sabon Gari, and Bagalam. These wastes are found in the Goulbi with the next rain.

1) Number and distribution of collection points

The number of uncontrolled dumps is difficult to identify because these sites are not listed, and their license proliferation. Some are, sometimes, emptied, while, others occur spontaneously. The containers are primarily distributed in the commercial, administrative and residential areas of the town center, their numbers and locations vary according to estimates of municipal services. Many suburbs are not served and have neither container nor official dumps. Wild dumps in these areas are therefore very numerous.

The lack of formal dumps and disposal service in outlying areas is a gap because if communal services do not have the means to regularly drain the official dumps, it will favor the proliferation of uncontrolled dumps which eventually invade neighborhood.

2) Material resources

At collection points, waste collection is provided by the municipalities. Containers and official dumps were emptied using bins. Each municipality of Maradi town has 1 bin.

3) Current organization of the collection.

The containers are emptied following a program established by the technical services according to the abundance of waste. The frequency of emptying containers is 3 to 4 times a week depending on the municipality. It is the same for official dumps. For District III, collection days are: Tuesday, Thursday, Saturday and sometimes Sunday. In fact, 11 to 14 containers are emptied daily. The collection hours are set from 7:00 AM to 2:00 PM. However, as we have seen, uncontrolled dumps are not subject to regular pickups.

People sometimes ask technical services intervention for disposal of these wastes, but rarely. Often schedules and frequencies of garbage are not respected if interventions are not planned. The machines are not always available, because the material is old and often breaks down (30 years old vehicle, Municipality III). Finally, the municipality complains of lack of fuel and lubricants (40 liter instead of 60 liters for Municipality III). The most glaring anomaly is the management of drivers that are uncontrollable and uncontrolled and whose actions are at the limit of "ecological crime".

Municipality III operates checks every month. A guarding system was put in place (2 dock guards for the Municipality I). The role of these guards is to control the discharge of waste by the population or pre-collectors; this will prevent the dumping of garbage around the containers. These guards can also help children to pay the waste in containers. According to officials, the guard allows proper maintenance of the containers, but it is often rendered useless by the failure to comply with waste removal program.

At the Municipality III, the leaders of hygiene and sanitation control daily regular garbage collection. Note that days of safety are organized on the occasion of some anniversary by women, youth, etc.

The waste transported must be dumped, by drivers, in landfills managed by Central municipality. However, only a small portion of the waste, estimated at about $10 \%$ actually reaches the landfill or near landfills.

The collection solid waste is often difficult due to its fragmentation around containers and in the dumps because of the wind, the trampling of animals and men, by lighting fires in containers and dumping wastewater around and in the container.

\subsection{Results of Household Surveys}

In total 340 people were surveyed and investigations involved both women and men according to their availability.

Table 3 shows that only $24 \%$ of women were surveyed, this is due to the refusal of some women from taking surveys.

In Table 4 hereafter, we see that $67 \%$ of respondents are married. Indeed, the amount of waste produced by households is even larger than the household consists of married people. The frequency we obtained (67\% for married) allows us to say that this is the basis of the significant increase in waste in the town of Maradi.

According to Table 5, 49\% of respondents have lifetimes in the town ranging from 25 - 45 years and only $20 \%$ are over 45 years old. This explains the recent urban development of Maradi town, a phenomenon that contributes to the proliferation of illegal dumpsites. For this, youth must occupy a central place in all activities within the scope of the Waste Management (awareness, environmental education...). 
Table 3. Frequency of respondents by sex.

\begin{tabular}{ccc}
\hline Sex & Number of respondents & Frequency (\%) \\
\hline Non-response & 0 & 0 \\
Male & 259 & 76 \\
Female & 81 & 24 \\
Total & 340 & 100 \\
\hline
\end{tabular}

Table 4. Frequency of respondents by marital status.

\begin{tabular}{ccc}
\hline Situation & Number of respondents & Frequency (\%) \\
\hline Non-response & 0 & 0 \\
Married & 228 & 67 \\
Single & 112 & 33 \\
Total & 340 & 100 \\
\hline
\end{tabular}

Table 5. Frequency of respondents according to their duration in the Maradi town.

\begin{tabular}{ccc}
\hline Duration & Number of respondents & Frequency (\%) \\
\hline Non-response & 0 & 0 \\
$<25$ years & 106 & 31 \\
25 to 45 years & 169 & 49 \\
$\geq 45$ years & 69 & 20 \\
Total & 340 & 100
\end{tabular}

The results of Table 6 show that $44 \%$ of people live in collective habitats against $56 \%$ for those individual types. However, this frequency should be considered because in collective type habitats, It may be possible to have more than 5 households, it can probably increase the amount of waste produced by a habitat.

Table 7 shows the results of investigation on the method of removing waste from 340 households under investigation (whether the collection and/or disposal by such and/or such mode). Municipal collection in Table 7 means the collection by bins or trucks on authorized dumps or door to door; as containers, it is of municipal waste. For districts that receive municipal collection, door to door collection is generally appreciated. Thus, the irregular collection, refusal and inability to pay for the service bring people to search for their waste disposal strategies. These wastes then follow multiple paths and tracks. If a fraction is recovered, reused or recycled, most is either dispersed on site or burned or transported to uncontrolled landfills or dumped on public roads sometimes as embankments, on farmland or wasteland, generating negative externalities (environmental degradation, various health problems, etc.).

Table 8 shows that more than half of residents evacuate their waste daily from their concession to public space. This demonstrates the clear desire of the people to get rid of their waste.

Table 9 gives answers relative to the satisfaction rate of collection by municipal services (at this level, we find that $35 \%$ of the population are not at all satisfied with the collection as it is performed currently by the municipalities).

However, it should be noted that people are aware of the problems created by uncontrolled dumps, but the inaccessibility of authorized dumps or containers and irregular collection that sometimes lead them to create wild dumps. In fact, it is this awareness that drives some people to sort or bury their waste in their concessions.

Table 10 showed that $48 \%$ keep livestock in the town of Maradi; this frequency is very high for a town like Maradi and this can significantly increase the production of particularly solid waste. 
Table 6. Frequency of respondents by type of habitat.

\begin{tabular}{ccc}
\hline Habitat & Nunber of respondents & Frequency (\%) \\
\hline Non-response & 0 & 0 \\
Individual & 190 & 56 \\
Collective & 150 & 44 \\
Total & 340 & 100 \\
\hline
\end{tabular}

Table 7. Rate of municipal collection.

\begin{tabular}{ccc}
\hline Municipal collection & Number of respondents & Frequency (\%) \\
\hline Non-response & 0 & 0 \\
Yes & 138 & 41 \\
No & 202 & 59 \\
Total & 340 & 100 \\
\hline
\end{tabular}

Table 8. Frequency of waste disposal.

\begin{tabular}{ccc}
\hline Disposal frequency & Number of respondents & Frequency (\%) \\
\hline Every day & 175 & 52 \\
Once a week & 27 & 8 \\
Twice a week & 60 & 18 \\
Three times a week & 74 & 22 \\
Total & 340 & 100 \\
\hline
\end{tabular}

Table 9. Frequency of satisfaction of municipal collection.

\begin{tabular}{ccc}
\hline Satisfaction & Number of respondents & Frequency (\%) \\
\hline Non-response & 0 & 0 \\
Very satisfied & 44 & 32 \\
Quite satisfied & 45 & 33 \\
Not all satisfied & 49 & 35 \\
Total & 138 & 100 \\
\hline
\end{tabular}

Table 10. Frequency of farming in the town.

\begin{tabular}{ccc}
\hline Farming & Number of respondents & Frequency (\%) \\
\hline Non-response & 0 & 0 \\
Yes & 164 & 48 \\
No & 176 & 52 \\
Total & 340 & 100 \\
\hline
\end{tabular}

\subsection{Different Actors Involved in the Waste Management in Maradi Town and Their Roles}

According to our analysis, we have identified actors as followed:

\subsubsection{Municipal Technical Offices}

Roles: 
- Establish and implement a comprehensive framework for waste management

- Organize the evacuation of lawful and lawless dumps

- Prohibit anarchic dumps

- Act as contracts pre-collection project

- Supervise the management of the landfill

- Support public awareness and mobilization

\subsubsection{Technical Offices of Hygiene and Sanitation}

Roles:

- To monitor the implementation of standards and regulations

- Supporting efforts of municipal services through awareness

- Support public awareness

- Monitor the implementation of the environmental monitoring program

- Support public awareness and mobilization

\subsubsection{Central Municipality of Maradi Town}

Roles:

- Select and recognize formally the structures responsible for monitoring and control,

- Support implementation of sanctions applied by the supervisory structures

- Finance dumps cleaning operations

- Encourage and formalize bins sites deposits

- Develop and follow a management contract for the landfill

- Establish an office for complaints about the activities of pre-collection and collection

- Coordinate sensitization and communication activities

\subsubsection{Neighborhood Leaders}

Roles:

- Ensure compliance with health regulations and safety

- Mediating conflicts

- Report to the municipalities waste producers offenses

- Monitor the sanitation of evacuated dumps places

- Encourage and formalize deposition sites bins

- Support awareness of their fellow citizens in their duties in the waste management and inform them of their legal obligations

\subsubsection{Neighborhoods Associations}

Roles:

- Report crimes committed by producers to their municipality

- Assist in the identification, removal and monitoring anarchic dumps

- Encourage sites deposits bins

- Support awareness of their fellow citizens in their duties in the management of waste and inform them of their legal obligations

\subsubsection{Teams of Pre-Collection}

Roles

- Educate households

- Pre-collect garbage in households

- Recover taxes according to the rates in vigor

- Assist in the identification, removal and monitoring anarchic dumps

- Encourage deposition sites bins,

- Use bins adequately

- Inform clients of their obligations upon accession or payment, support awareness for behavior change in general 


\subsubsection{Residents in Neighborhoods}

Roles:

- Adhere to the project

- Perform the agreed fee

- Condition best the garbage

- Assist in the identification, removal and monitoring anarchic dumps

- Apply the decisions of change and the knowledge gained

\subsubsection{Non-Governmental Organizations}

Role:

To finance all activities within the scope of waste management.

\subsubsection{Researchers}

Role:

To be actors for solid waste management in the Sahelian cities [22].

\section{Discussion: Assessment, Analysis and Interpretation}

In light of interviews, surveys and field visits undertaken as part of this study we note today that efforts are being made by those involved in waste management in order to improve the safety of the town of Maradi.

These efforts are revealed through: the development and implementation of a system of waste management in continuous improvement. Thereto, the division of the cleanliness of the DST, control the smooth running of the pre-collection and collection. She watches, with the support of partners in the development, of transit centers and final discharge. She collaborates with the direction of the environment that already has the texts and laws regulating the proper management of garbage. However, the collaboration of the DST with other institutions, even if it is already encouraging, it is still at the embryonic level. Thus, despite efforts to better urban waste management, we note, as a result of the inventory done in this study, several challenges and constraints faced.

\subsection{Inventory}

We propose to our attention here on the following aspects related to waste:

1) The behavior of the population

2) Proliferation of disease vectors and health risks

3) Environmental pollution

First, with regard to the behavioral aspect, we say that it is the basis of the proliferation of uncontrolled dumps. Failure subscription of households are forced them to dump their garbage anarchically. The storage and use of inappropriate garbage for those subscribers is another problem to solve. We note therefore:

4) Pollution of the atmosphere and the release of noxious odors caused particular by gas from landfills;

5) Degradation of the aesthetics of the town and the immobilization of productive lands due to the presence of non-biodegradable products (e.g. plastic bags, demolition waste, etc.);

6) Soil contamination by leachate which may contain hazardous chemicals (pesticides, heavy metals, etc.), degradation of soil quality and water, phenomenon that induces the proliferation of disease vectors such as flies, mosquitoes, rats, cockroaches. Also, burning garbage releases toxic gases that affect air quality.

As mentioned in the results section, the experience of other countries (including Egypt and Zimbabwe, two countries in Africa) demonstrated that people are willing to pay for waste collection services if they are effective and if an appropriate mechanism for collecting the charges and penalties for non-payment are established [23].

In the current context of overlay management system, three aspects that we consider essential are indispensable to the establishment of a system of sustainable waste management in Maradi town.

This is a clear and strong political determination, the full involvement of the people and controls the financial and technical aspects within a coherent organizational system.

Clear and strong political motivation is a provided prerequisite for any sustainable system of waste management in Maradi town. Although there are laws regulating waste management nationally, their application remains to be desired. However, political commitment must go beyond the development of some regulations. The latter must provide practical solutions to problems related to various aspects of the urban waste management 
answers. Each actor must be able to fulfill its responsibilities both technical and organizational.

Public involvement should take into account the cultural dimension, but also the poverty of the people. The more we produce than we discharged in the South as in Niger, waste becomes increasingly insupportable encumber. This charge is inconceivable for the vast majority of the population. In other words, the information, education, communication and public awareness should be key elements. Given the economic difficulties of the people, the ability for them to pay should not be left out. Citizens must engage, propose, and monitor activities. It must be the starting point and the end point of any strategy.

Economic and financial aspects are, in turn, leading sustainability factors of the system. In Maradi and generally in Niger, the vast majority of failures are due to financial problem. Royalties received are low and the town budget is very limited.

Indeed, in Niger, we find an urban population composed of a high proportion of poor people with very lowincome and largely illiterate. Hence, it is very necessary to implement other forms of mobilizing financial resources (financial innovation). This should be based primarily on reducing costs of collection to disposal. This cost reduction should be accompanied by a maximum reduction of waste (reduce, reuse, recycling/recovery) and collected for disposal.

Today, logic dictates that the solid waste management is paid by those who produce them, according to the polluter pays principle. Its application can be complex at the household, for reasons of inability to pay for the service, by a large proportion of the population. Another admirable aspect is the consent to pay expressed by a section of the population. Indeed, Coulibaly conducted, on the topic, a study based on the contingent valuation method [24]. Conducted among 141 households, this study reveals a greater acceptance of the private pricing versus the municipal services. Thus, it highlights the increased confidence of the population to services provided by the private sector. The reasons could be related to the greater proximity and flexibility of the private, and a flexible fee in the amounts to be collected. Thus, two handicaps appear for this part of the funding:

- The real ability of people to pay (part of the population is therefore not fulfilling royalties).

- Lack of trust with respect to local authorities (part of the income of the pre-collection is not controlled).

As against, the principle should be established and strictly enforced, especially for "big polluters". For all activities generating waste, the application of the polluter-pays principle should lead to a significant contribution of the informal sector in waste management. Moreover, this principle will promote the development of awareness to lead large real polluters to finance part of the waste management of the poor.

\subsection{Proposed Strategy for Improving the Current System of Urban Waste Management}

\subsubsection{Sensitization}

Awareness and training are essential axes to strengthen in order to change behavior and encourage involvement at the base within populations. To achieve this, the mass media can play a vital role in explaining the risks to people when they throw garbage anarchically and benefits that can provide their subscription to pre-collection structures. An awareness campaign for households will effectively get them to recognize their responsibility for the pollution. Thus, a mass awareness (newspapers, radio, television) supplemented by awareness of proximity organized for households (communication door to door, school diversion, theater). Regarding the mass awareness, urban waste management actors should be invited, regularly, for programs and broadcast debates; perform a wide poster campaign to the streets on the issue of waste. In schools, students will be targeted as opinion vectors through sensitivity training: awareness modules in waste management can be introduced into the curriculum; the realization of theater by students on the theme. Awareness must also involve mosques and churches where imams and priests, pastors will enjoy a time of true awareness of the risks associated with waste. Awareness should focus on reducing waste generation at the individual level, the individual management of waste products, the health risks associated with waste, poor sanitation and other environmental problems.

\subsubsection{Combining Outreach and Sanctions}

Awareness achieved without concrete support measures, including prevention and repression carried out by the municipal service ends up being ineffective. The risk is that people consider they can continue to throw away their waste in public places. To promote behavior change, awareness is not always sufficient. Municipal police should be put in place as complement to awareness. 


\section{Conclusion and Recommendations}

In light of our study, it is clear that the current system of waste management in the town of Maradi fails. Indeed, there is no political will to make the urban waste management a priority; the texts governing the management of urban waste are not applied; the institutions involved in the urban waste management do not collaborate effectively; the effective control measures of the activity of the urban waste management providers is absent; the financial, human and technical (a consequence of repeated dump trucks collecting failures) resources are not adequate; the presence of the presence of unfair competitors (carters) in the field of pre-collection prevents proper ownership of the areas by the pre-collection structures; the frequency of garbage collection and sewage following the failure of trucks and bins is not observed; a plan for education and information on the management of municipal solid waste is absent; the inappropriate trash for pre-collection is used; the garbage collection with taking large amounts of sand is not selective; the cost of pre-collection too high for some households should be estimated.

Faced with these limitations, the capacity of stakeholders in the waste management through seminars and conferences must be reinforced; the evaluation of executed work must be followed-up; the additional efforts in raising awareness and educating the public through regular campaigns, targeting more women and young people should be done; the regulations in force concerning the urban waste management should be implemented; the pathways carts neighborhoods to facilitate the collection of waste in different neighborhoods with dump trucks should be rehabilitated.

In research, our work can provide an opening for further studies in the field of waste management in Maradi. Moreover, it appears necessary to continue this work by integrating other areas of research such as the study of the behavior, practices and attitudes of the population of the town of Maradi for household waste, the characterization of solid waste from the town of Maradi, and the analysis of internal costs of disposal options and treatment of household waste and wastewater.

\section{References}

[1] Barles, S. (2005) History of Waste Management and the Social and Cultural Representations of Waste.

[2] Productivity Commission Inquiry Report $N^{0} 36,2006$. Waste Management.

[3] Daniel, H. and Perinaz, B.T. (2012) What a Waste in: A Global Review of Solid Waste Management. No. 15.

[4] (2008) Practical Action Nepal, Best Practices on Solid Waste Management of Nepalese Cities.

[5] Schulze, C. (2013) Municipal Waste Management in Berlin. Berlin Senate Department for Urban Development and the Environment Communication.

[6] Swedish Environmental Protection Agency (2005) A Strategy for Sustainable Waste Management.

[7] Adewole, T.A. (2009) Waste Management towards Sustainable Development in Nigeria: A Case Study of Lagos State. International Non-Governmental Organization (NGO) Journal, 4, 173-179.

[8] (2013) Asian Development Bank, Solid Waste Management in Nepal. Current Status and Policy Recommendations.

[9] Rouse, J.R. (2004) Solid Waste Management in Emergencies. WHO Regional Office for South-East-Asia. Technical Note $\mathrm{N}^{0} 7$.

[10] Faris, K., Alemayehu, T., Wubshet, M. and Hailu, D. (2002) Human and Other Liquid Waste Management. Ethiopian Public Heath Training Initiative (EPHTI).

[11] Bogner, J., Ahmed, M.A., Diaz, C., Faaij, A., Gao, Q., Hashimoto, S., Mareckova, K., Pipati, R. and Zhang, T. (2007) Waste Management. In: Metz, B., Davidson, O.R., Bosch, P.R., Dave, R. and Meyer, L.A., Eds., Climate Change: Mitigation, Cambridge University Press, Cambridge and New York, 586-618.

[12] World Health Organization (1991) United Nations Environment Protection (UNEP). WHO, Geneva.

[13] NEST (1991) Nigeria’s Threatened Environment: A National Profile. Environmental Study/Action Team, NEST, Ibadan.

[14] UNDP/NISEPA (2009) Niger State Framework for Integrated Sustainable Waste Management. Niger State Strategic Waste Management Framework.

[15] Solomon, U.U. (2009) The State of Solid Waste Management in Nigeria. Waste Management, 29, 2787-2788. http://dx.doi.org/10.1016/j.wasman.2009.06.030

[16] Babalola, A., Ishaku, H.T., Busu, I. and Majid, M.R. (2010) The Practice and Challenges of Solid Waste Management in Damaturu, Yobe State, Nigeria. Journal of Environmental Protection, 1, 384-388. 
http://dx.doi.org/10.4236/jep.2010.14044

[17] Arma, O. (2012) Food Livestock: Supply Circuit and Valuations in the Urban Community of Maradi. Internship Report, Masters Degree in Agricultural-Science, 54 p.

[18] Cerie, C. (2009) Environmental Impact Assessment Report of the Project of the Discharge of Maradi.

[19] National Statistics Institute (2010) Statistical Yearbook Least Fifteen Years of Independence of Niger. INS, 338 p.

[20] Trading Company of Niger (2009) Impact Assessment Environmental Report of tannery of Maradi, 138 p.

[21] Infrastructure Rehabilitation Project (IRP) (2000) Basic Study for Solid Waste Management, Diagnosis of the Sector of Municipal and Industrial Solid Waste in the Urban Community of Niamey, Volume1, Final Report, 105 p.

[22] Tini, A. (2003) Solid Waste Management in Niamey, Niger: Trial for Sustainable Management Strategy. Ph.D. Thesis, Institute of Applied Sciences, Lyon, 306 p.

[23] Adepoju, G.O. (2001) Urban Waste Management: Solutions for Africa. Editions IDRC, Ottawa.

[24] Coulibaly, S. (2000) Costs of Removal of Household Solid Waste and Analysis of the Determinants of Willingness to Pay of Households. For Ouagadougou Ordinary Class Neighborhoods. Master’s Thesis, University of Ouagadougou, Faculty of Economics and Management (FASEG), Ouagadougou, 73 p. 